\title{
Loss of HDAC5 Impairs Memory Function: Implications for Alzheimer's Disease
}

\author{
Roberto Carlos Agis-Balboa ${ }^{\mathrm{a}, *}$, Zsuzsa Pavelka $^{\mathrm{a}}$, Cemil Kerimoglu ${ }^{\mathrm{a}}$ and Andre Fischer ${ }^{\mathrm{a}, \mathrm{b}}$ \\ ${ }^{a}$ Department of Psychiatry and Psychotherapy, University Medical Center Göttingen, Göttingen, Germany \\ ${ }^{\mathrm{b}}$ German Center for Neurodegenerative Diseases (DZNE) Göttingen, Göttingen, Germany
}

Handling Associate Editor: Israel Ampuero

Accepted 9 July 2012

\begin{abstract}
Epigenetic mechanisms such as histone-acetylation have been implicated with learning and memory and are believed to contribute to the pathogenesis of neurodegenerative diseases such as Alzheimer's disease (AD). Histone-deacetylase (HDAC) inhibitors were shown to exhibit neuroprotective and neurodegenerative properties in AD animal models, and targeting HDACs appears to be a promising therapeutic strategy for brain diseases. The role of the distinct HDAC proteins in the adult brain is, however, not well understood and so far only pan-HDAC inhibitors have been tested in preclinical settings. Understanding the role of individual HDACs in cognition and AD pathogenesis is therefore vital to develop more selective HDAC inhibitors for the treatment of AD. In this study we investigated the role of HDAC5 in memory function and AD pathogenesis. We show that loss of HDAC5 impairs memory function but has little impact on pathogenesis in a mouse model for amyloid pathology. Our data reveals a novel role of HDAC5 in memory consolidation and shows that future approaches to develop more selective HDAC inhibitors for the treatment of AD should avoid targeting HDAC5.
\end{abstract}

Keywords: Alzheimer's disease, amyloid pathology, epigenetics, HDAC inhibitors, histone deacetylases, learning and memory, neurodegenerative diseases

\section{INTRODUCTION}

Epigenetic mechanisms, such as DNA methylation and covalent histone modifications, govern gene expression in a manner that is independent of the DNA-blueprint [1]. This can provide an opportunity to elucidate gene-environment interactions in complex diseases such as Alzheimer's disease (AD) that are a burden for our modern society with a continued extension of life expectancy $[2,3]$. The precise molecular mechanisms underlying this age-related cognitive decline observed in AD is still not well understood.

*Correspondence to: Roberto Carlos Agis-Balboa, University Medical Center Göttingen, Grisebach Str. 5, 37077 Göttingen, Germany; Department of Psychiatry and Psychotherapy, German Center for Neurodegenerative Diseases (DZNE) Göettingen, Germany. Tel.: +49 551 399834; Fax: +49 551 399836; E-mail: r.balboa@gwdg.de.
Histone-deacetylase (HDAC) proteins act in concert with histone acetyltransferases and remove the acetyl groups from histone and non-histone proteins [4]. The human and rodent genome encodes 11 HDAC proteins that are classified in four families HDAC I-IV: class I (HDAC 1-3, HDAC8), class IIa (HDAC 4, 5, 7 and 9), class IIb (HDAC 6 and 10), and class IV (HDAC 11). Previous studies demonstrated that panHDAC inhibitors such as sodium butyrate, trichostatin A, suberoylanilide hydroxamic acid, or sodium phenylbutyrate could be a possible therapeutic approach to treat age-associated dementias such as AD [2, 5-12] even at advanced states of disease progression [13].

Which of the 11 HDAC proteins is most important for the beneficial effect of pan-HDAC inhibitors is currently not well understood. While recent data support the view that HDAC2, a class I HDAC, is a restraint of memory function [14] and implicated with AD pathology [15] possibly via the regulation of histone 4 lysine 
12 acetylation mediated gene-expression [8], the role of class II HDACs in AD has not been explored in detail.

Thus, we decided to investigate the role of HDAC5, a class II HDAC, that can shuttle between the nucleus and the cytosol and deacetylates MEF2 [16], which is essential for synaptic plasticity. Moreover, HDAC5 has been associated previously with behavioral adaptations to emotional stimuli such as cocaine addiction [17-19]. Thus, our aim was to test the hypothesis that targeting HDAC5 could be a suitable strategy to treat cognitive decline linked to AD pathogenesis. In contrast to this hypothesis, our data shows that HDAC5 is essential for memory consolidation in mice and that loss of HDAC5 does not improve cognition in a mouse model for AD. This data provides two important findings. First, future HDAC inhibitors for the treatment of AD should avoid targeting HDAC5 and second, strategies that increase, rather than inhibit HDAC5 could serve as novel therapeutic approaches.

\section{MATERIALS AND METHODS}

\section{Animals}

Mice were housed under standard conditions with free access to food and water $a b$ libitum. All experiments were approved by the Animal Committee of the state of Lower Saxony, Germany. The genetic background of all mice was C57BL/6J. The APßP/PS1-21 mouse model used for our experiments, a double transgenic Thy1-AßPP (KM670/671NL) and Thy1-PS1 (L166 P), was first described by Radde et al. [20]. HDAC5 mutant mice were originally described by McKinsey et al. [21].

\section{Behavioral analysis}

Behavior testing was performed as described previously [8, 22, 23]. In brief, mice were single housed and habituated to the testing room 1 week before behavior experiments. Tests were conducted when the mice were 10-months of age. Mice were subjected to a battery of behavioral tests: open field, elevated-plus maze, context/tone fear conditioning, and Morris water maze. Unless otherwise indicated, the results present pooled data from male and female mice in case two way ANOVA showed no gender-related difference among groups. For the open field test, mice were placed in the center of a plastic arena (length $1 \mathrm{~m}$; width $1 \mathrm{~m}$; side walls $20 \mathrm{~cm}$ height) for $5 \mathrm{~min}$. The explorative behavior was recorded by a camera and analyzed using the VideoMot2 software (TSE Systems). For elevated plus maze analysis, mice were placed in the center region of the elevated maze facing the open arm. The behavior was recorded for 5 min using the VideoMot 2 system (version 5.72; TSE systems). Fear conditioning training was performed using the TSE fear conditioning system. The procedure consisted of exposing mice to the conditioning context $(3 \mathrm{~min})$ followed by a single electric footshock $(0.7 \mathrm{~mA}$, constant current, $2 \mathrm{~s})$. Afterward, mice were left in the conditioning box for $15 \mathrm{~s}$ before being returned to their home cage. Freezing was analyzed $24 \mathrm{~h}$ later during re-exposure to the conditioning context. For tone-dependent fear conditioning, a tone $(10 \mathrm{kHz}, 75 \mathrm{db})$ was presented for $30 \mathrm{~s}$ prior to the footshock and tone-dependent memory was tested by placing the mice into a novel context for $1 \mathrm{~min}$ followed by $3 \mathrm{~min}$ exposure to the conditioning tone. Water maze training was performed in a circular tank (diameter $1.2 \mathrm{~m}$ ) filled with opaque water. A platform $(11 \times 11 \mathrm{~cm})$ was submerged below the water's surface in the center of the target quadrant. The swimming path of the mice was recorded by a video camera and analyzed by the Videomot 2 software (TSE). For each training session, the mice were placed into the maze subsequently from four random points of the tank and were allowed to search for the platform for $60 \mathrm{~s}$. If the mice did not find the platform within $60 \mathrm{~s}$, they were gently guided to it. Mice were allowed to remain on the platform for $15 \mathrm{~s}$. On day 10, mice were subjected to one memory test (probe trial) $24 \mathrm{~h}$ after the last training session. During the probe test the platform was removed from the tank and the mice were allowed to swim in the maze for $60 \mathrm{~s}$.

\section{Quantitative real-time PCR ( $q P C R)$}

Total RNA was isolated using the TRI reagent (Sigma-Aldrich, Steinheim Germany) according to the manufacturer's instructions. RNA was dissolved in $30 \mu \mathrm{l}$ ddH2O. qPCR was performed using a Roche 480 Light Cycler (Roche, Mannheim, Germany). cDNA was synthesized from $1 \mu \mathrm{g}$ of total RNA using the iScript cDNA Synthesis Kit (BIORAD, Hercules, USA) according to the manufacturer's instructions. Expression of individual genes was analyzed using the Roche Universal Probe Library (UPL). The housekeeping gene hypoxanthine phosphoribosyltransferase 1 (Hprtl) was chosen as an internal reference for normalization of gene expression. To detect the human App transgene we used 
the following primers and UPL probes: Hprt1-L 5' TCCTCCTCAGACCGCTTTT-3' (UPL \#95); Hprt1R 5'-CCTGGTTCATCATCGCTAATC-3' (UPL \#95); $h A p p-\mathrm{L} 5^{\prime}$-CCTGGTGATCCATGTCAGAA- $3^{\prime}$ (UPL \#11); hApp-R 5'-AAACACTGCCAAGGTGTCAA-3' (UPL \#11).

\section{Immunoblot analysis}

Proteins were isolated using the TRI reagent (SigmaAldrich, Steinheim, Germany) according to the manufacturer's instructions. Proteins were dissolved in $3 \mathrm{M}$ urea in $0.01 \mathrm{M}$ PBS using an ultrasonic homogenizer for $10 \mathrm{~s}$, at 8 cycles and $85 \%$ power (Bandelin Electronic, Berlin, Germany). For immunoblot analysis, protein lysates were mixed with Laemmli loading buffer, heated at $98^{\circ} \mathrm{C}$ for $3 \mathrm{~min}$, centrifuged shortly, and stored at $4^{\circ} \mathrm{C}$. Individual proteins were resolved on a $12 \%$ SDS-polyacrylamide gel by electrophoresis (Bio-Rad, Germany) at $120 \mathrm{~V}$. The PageRuler Prestained Protein Ladder (Fermentas, Germany) was taken as molecular weight standard. After resolution, the proteins were transferred to a nitrocellulose membrane at $60 \mathrm{~V}$ for $16 \mathrm{~h}$ on ice at $4^{\circ} \mathrm{C}$. The membrane was washed in $0.01 \mathrm{M}$ PBS at room temperature (RT) and incubated in 5\% milk prepared in $0.01 \mathrm{M}$ PBS at RT for $1 \mathrm{~h}$ to block non-specific sites. Primary antibody dissolved in $0.5 \%$ milk in $0.01 \mathrm{M}$ PBS was used to probe the membrane at $4{ }^{\circ} \mathrm{C}$ overnight on a shaker. The antibodies used were: mouse $A \beta_{17-24}$ (4G8) $(1: 1000$, Convance) and anti-Actin $(1: 1000$, Santa Cruz). IRDye $800 \mathrm{CW}$ or $680 \mathrm{CW}$ conjugated polyclonal anti-mouse or anti-rabbit IgG cross-adsorbed secondary antibodies (1:15000, LICOR) were dissolved in $0.5 \%$ milk in $0.01 \mathrm{M}$ PBS, added on the membrane and incubated for $30 \mathrm{~min}$ at RT on a shaker in the dark. Unspecific binding was washed using $0.01 \mathrm{M}$ PBS thrice for $10 \mathrm{~min}$. Detection was performed using the Odyssey IR Scanner.

\section{Immunohistochemistry}

Immunostaining and quantification was performed as described previously [13, 23] and analyzed using a Leica SP2 confocal microscope. The following antibodies were commercially purchased and used in the mentioned concentrations: NeuN (1:1000; Chemicon); Map2 (1:1000, Synaptic Systems); synaptophysin (Svp38) (1:1000, SigmaAldrich); synaptoporin (1:1000, Synaptic Systems); and $A \beta_{17-24}$ (4G8) (1:1000, Convance).

\section{Statistical analysis}

The data was analyzed by unpaired student's $t$-test and two-way ANOVA (ANalysis Of VAriance) when appropriate. Bonferroni post-hoc test was used with two-way ANOVA analysis. Errors are displayed as standard error of the mean (SEM). Graphs were generated using GraphPad Prism.

\section{RESULTS}

The present study was designed to address two questions: 1) to analyze the role of HDAC5 in memory consolidation; and 2) to investigate if HDAC5 would affect disease pathology and cognitive function in a mouse model for AD. Thus we set up breeding among A $\beta P P / P S 1-21$ mice that exhibit aggressive amyloid- $\beta$ plaques pathology [20] and mice that lack HDAC5 [24] to obtain 4 experimental groups: wild type control mice (WT), HDAC5 knockout mice (HDAC5 -/-), A $\beta P P / P S 1-21$ mice (A $\beta P P)$, and A $\beta P P / P S 1-21$ mice that lack HDAC5 (A $\beta P P-H D A C 5-/-)$. Since robust memory impairment can be detected in 8-12 month old A $\beta P P$ mice $[13,20]$, we decided to perform molecular and behavioral analysis of all groups in 10-month old animals. We measured spatial memory performance using the hippocampus-dependent Morris water maze test. All groups except the AßPP-HDAC5 -/group improved in their ability to find the hidden platform throughout the training days (Fig. 1A) and showed a significantly reduced escape latency when comparing the last versus the first day of training (Fig. 1B). This effect was neither due to alterations in the swimming distance nor the swimming speed that was similar among groups (Fig. 1C, D). Also, no sign of thigmotaxis was observed in any of the groups. When the probe test was performed $24 \mathrm{~h}$ after the last day of training, only WT mice, but none of the other groups, showed a significant preference for the target quadrant (Fig. 1E). When the number of platform crossings, a sensitive measure of spatial memory was analyzed, we observed that all groups were impaired when compared to WT mice (Fig. 1F). Although the interaction among the two variables A $\beta P P$ and HDAC5 was not significant (Interaction: $\left.\mathrm{F}_{(1,42)}=2.12, p=0.15\right)$, the main effect of HDAC5 $-/-$ on platform crossings was significant (Hdact5 - --: $\left.\mathrm{F}_{(1,42)}=11.96, p<0.01\right)$. Bonferroni post-hoc test indicated that in mice without A $\beta P P$ pathology, lack of HDAC5 had a significant effect (WT versus HDAC5 - - , $p<0.01)$. The main effect of A $\beta P P$ pathology on platform crossings was borderline 

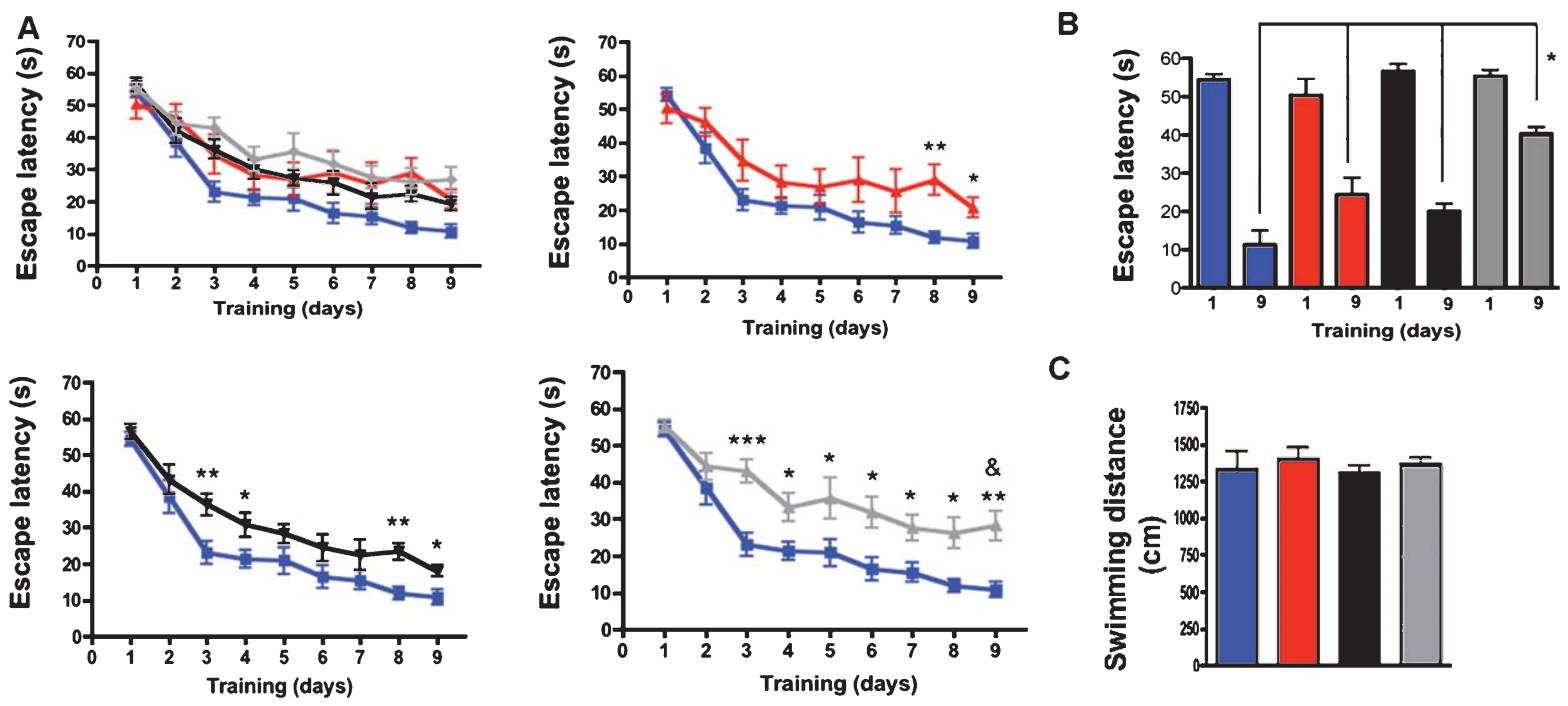

C

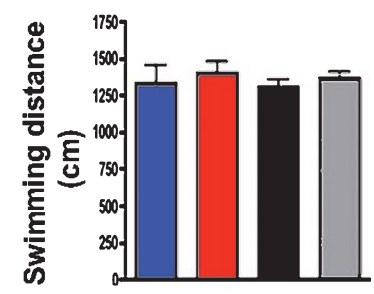

\section{E}

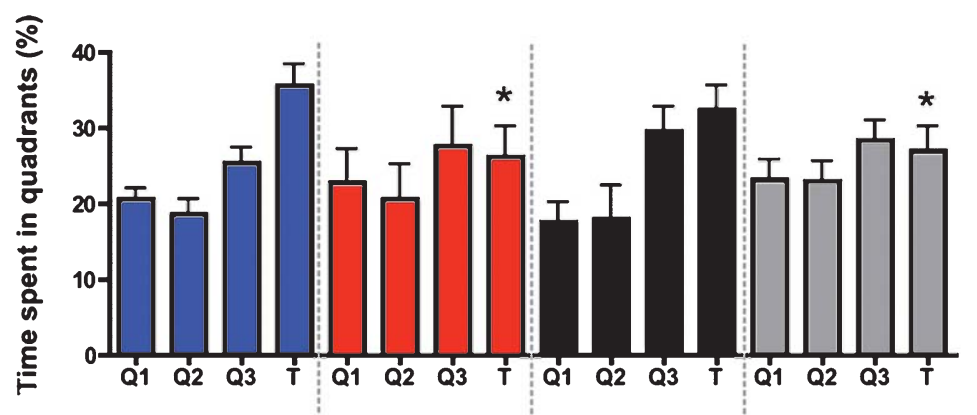

D
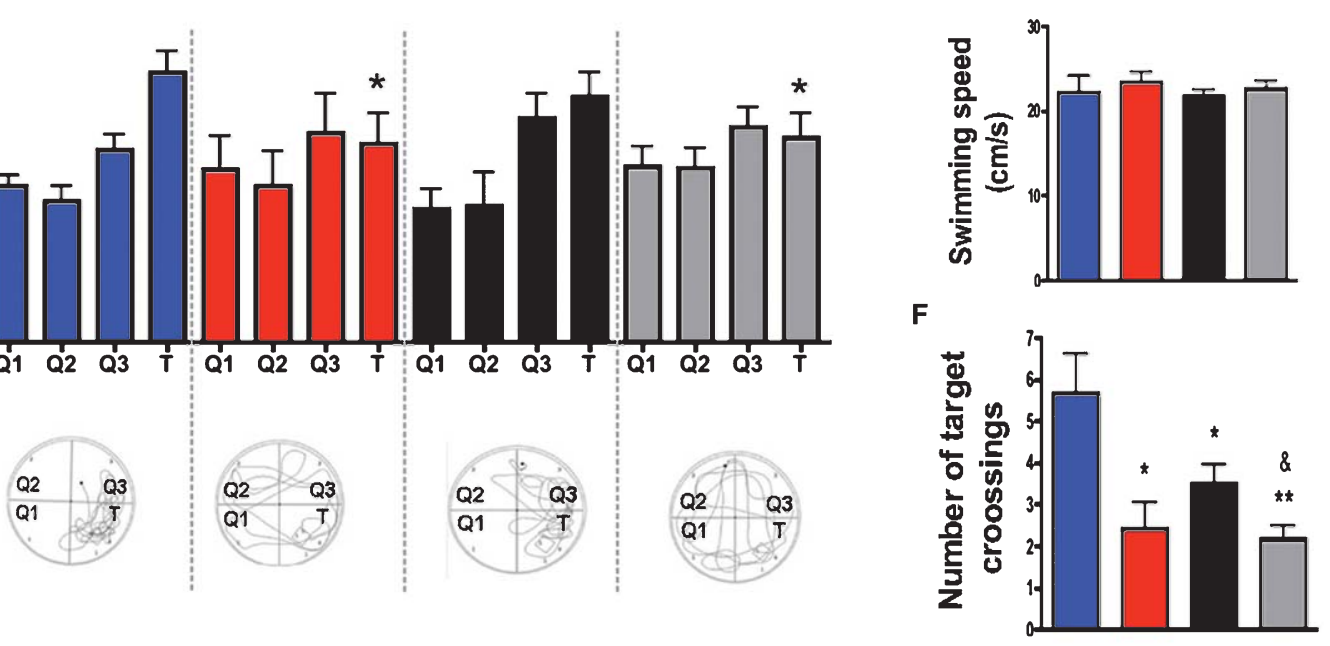

ABPP-HDAC5 - -

Fig. 1. Impaired spatial memory formation in HDAC5 -/- mice. A) When compared to the WT group, the escape latency throughout the training was significantly impaired in 10-month-old HDAC5 - /-, A PPP, and A PPP-HDAC5 -/- mice using two-way ANOVA with repeated measurements. For clarification, the pooled data comparing all 4 groups is shown along with the graphs depicting individual comparisons to the WT control group. WT versus HDAC5 - /-: (Interaction (Genotype \& Time): $\mathrm{F}_{(8,128)}=1.77, p=0.08$; Genotype: $\mathrm{F}_{(1,128)}=6.04, p<0.05$; Time: $\left.\mathrm{F}_{(8,128)}=28.91, p<0.0001\right\}$; WT versus A $\beta P P$ : (Interaction (Genotype \& Time): $\mathrm{F}_{(8,176)}=0.84, p=0.56$; Genotype: $\mathrm{F}_{(1,176)}=11.88$, $p<0.01$; Time: $\left.\mathrm{F}_{(8,176)}=45.43, p<0.0001\right\}$; WT versus A $\beta$ PP-HDAC5 -/-: (Interaction (Genotype \& Time): $\mathrm{F}_{(8,176)}=2.02, p<0.05$; Genotype: $\mathrm{F}_{(1,176)}=15.71, p<0.001$; Time: $\left.\mathrm{F}_{(8,176)}=32.98, p<0.0001\right\} .{ }^{*} p<0.05,{ }^{* *} p<0.01$, and ${ }^{* * *} p<0.001$ versus WT; ${ }^{*} p<0.05$ versus A $\beta P P$ using student's $t$-test. B) Escape latency was compared on day 1 versus the last day (day 9) of training. Day 1: (Interaction: $\mathrm{F}_{(1,40)}=0.00, p=0.99$; Hdact5-I-: $\left.\mathrm{F}_{(1,40)}=0.13, p=0.72 ; \mathrm{A} \beta P P: \mathrm{F}_{(1,40)}=0.59, p=0.44\right) ;$ Day 9: $\left(\right.$ Interaction: $\mathrm{F}_{(1,40)}=0.13, p=0.72 ;$ Hdact5-/-: $\mathrm{F}_{(1,40)}=7.28, p<0.05$; A $\left.\beta P P: \mathrm{F}_{(1,40)}=4.89, p<0.05\right)$. While all groups improved in their ability to find the hidden platform, A PPP-HDAC5 - /- mice performed significantly worse than the other groups $\left({ }^{*} p<0.05\right.$ using student's $t$-test). C) Swimming speed during the days of training was similar among groups (Interaction: $\mathrm{F}_{(1,53)}=0.00, p=0.94 ;$ Hdact5 -/-: $\mathrm{F}_{(1,53)}=0.51, p=0.47 ; \mathrm{A} \beta P \mathrm{P}: \mathrm{F}_{(1,53)}=0.13, p=0.72$ ). D) Swimming speed during the days of training was similar among groups (Interaction: $\mathrm{F}_{(1,53)}=0.00, p=0.95 ;$ Hdact $\left.-/-: \mathrm{F}_{(1,53)}=0.51, p=0.47 ; \mathrm{A} \beta P P: \mathrm{F}_{(1,53)}=0.12, p=0.72\right)$. E) After 9 days of training, mice were subjected to a probe trial. The time spent in the target quadrant was significantly impaired in HDAC5 -/and A $\beta$ PP-HDAC5 $-/$ - mice when compared to the WT control group $\left({ }^{*} p<0.05\right.$ using student's $t$-test). Target preference in A $\beta P P$ mice was not significantly different to the WT group $(p=0.10)$, however, $\mathrm{A} \beta \mathrm{PP}$ mice failed to discriminate between the target quadrant $(\mathrm{T})$ and quadrant $3(\mathrm{Q} 3)$ indicating that the $\mathrm{A} \beta \mathrm{PP}$ mice also display impaired spatial memory consolidation (Interaction: $\mathrm{F}_{(1,40)}=0.35, p=0.55 ;$ Hdact5 -l-: $\mathrm{F}_{(1,40)}=4.54$, $\left.p<0.05 ; \mathrm{A} \beta \mathrm{PP}: \mathrm{F}_{(1,40)}=0.13, p=0.71\right) .{ }^{*} p<0.05$ versus WT using student's $t$-test. $\left.\mathrm{F}\right)$ The number of target crossings during the probe test was significantly reduced in HDAC5 - - , A $\beta P P$, and A $\beta$ PP-HDAC5 - /- mice when compared to the WT group. Interaction: $\mathrm{F}_{(1,42)}=2.12, p=0.15$; Hdact5 -/-: $\mathrm{F}_{(1,42)}=11.96, p<0.01 ; \mathrm{A} \beta P P: \mathrm{F}_{(1,42)}=3.36, p=0.07 .{ }^{*} p<0.05$ and ${ }^{* *} p<0.001$ versus WT; ${ }^{\&} p<0.05$ versus A $\beta P P$ using student's $t$-test. T, target quadrant, Q1, quadrant 1; Q2, quadrant 2; Q3, quadrant 3; Q4, quadrant 4. $n=16-20$ /group. Error bars indicate SEM. 
A
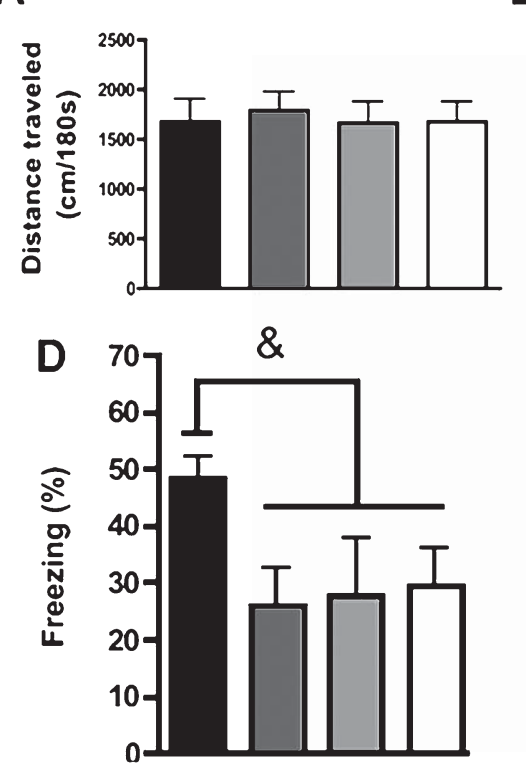

B

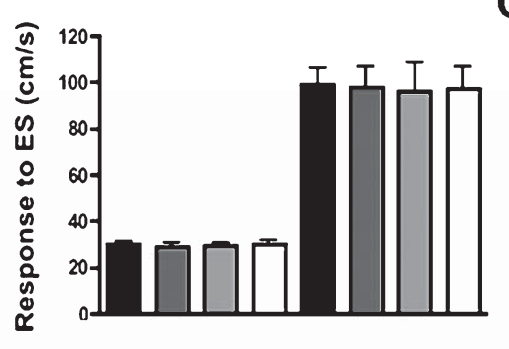

C
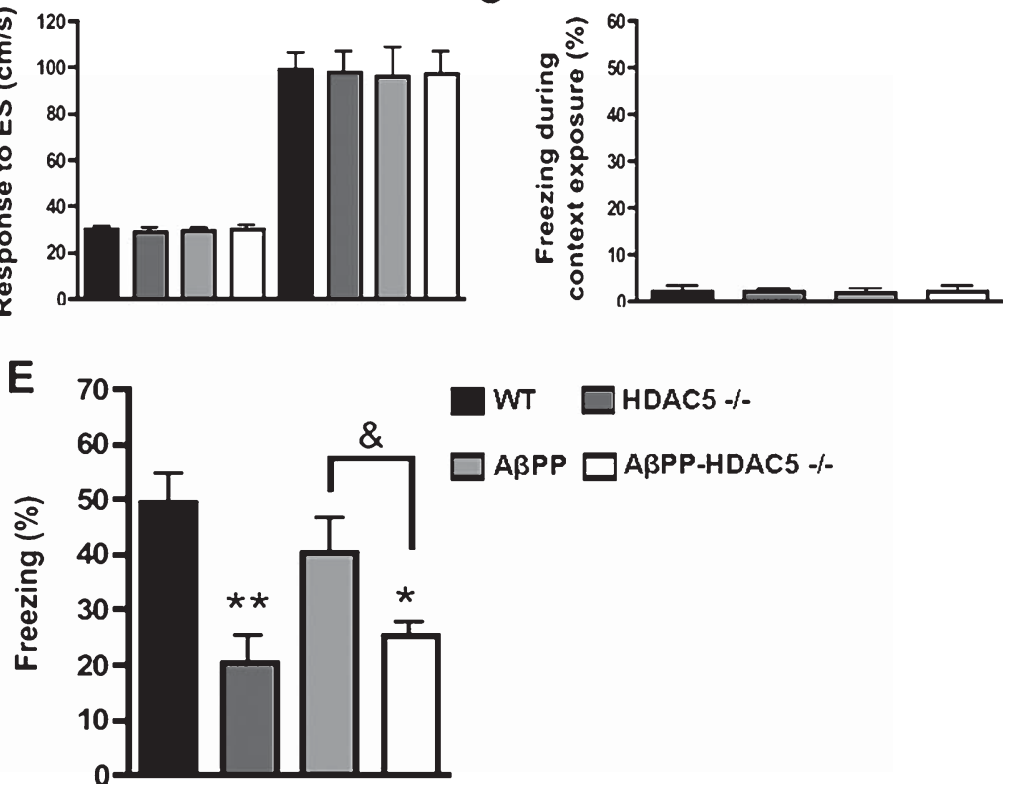

Fig. 2. Loss of HDAC5 impairs associative memory consolidation. A) Total distance covered in the novel context $\left(\right.$ Interaction: $\mathrm{F}_{(1,32)}=0.06$, $p=0.80 ;$ Hdact5 -/-: $\mathrm{F}_{(1,32)}=0.08, p=0.77$; A $\left.\beta P P: \mathrm{F}_{(1,32)}=0.09, p=0.77\right)$. B) Response to electric shock (ES) shown by maximum velocity before (pre-ES) and after the ES. Pre-ES (Interaction: $\mathrm{F}_{(1,32)}=0.19, p=0.66 ;$ Hdact5 -/-: $\left.\mathrm{F}_{(1,32)}=0.00, p=0.95 ; \mathrm{A} \beta P P: \mathrm{F}_{(1,32)}=0.01, p=0.94\right)$; ES (Interaction: $\mathrm{F}_{(1,32)}=0.02, p=0.90 ;$ Hdact5 -l-: $\mathrm{F}_{(1,32)}=0.00, p=1.00$; A $\left.\beta P P: \mathrm{F}_{(1,32)}=0.04, p=0.84\right)$. C) Basal freezing behavior shown upon context exposure (Interaction: $\mathrm{F}_{(1,32)}=0.12, p=0.72 ;$ Hdact5 -/-: $\left.\mathrm{F}_{(1,32)}=0.01, p=0.94 ; \mathrm{A} \beta P P: \mathrm{F}_{(1,32)}=0.01, p=0.94\right)$. D) Freezing

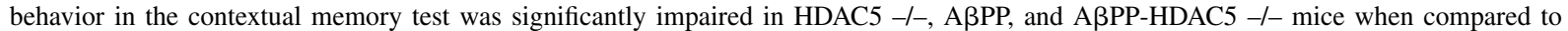
the WT control group (Interaction: $\mathrm{F}_{(1,37)}=16.65$, $p<0.001 ;$ Hdact5 -l-: $\mathrm{F}_{(1,37)}=29.12, p<0.001 ; \mathrm{A} \beta P P: \mathrm{F}_{(1,37)}=6.64, p<0.05$ ). Bonferroni post-hoc test indicated that in mice lacking A $\beta P P$ pathology, the lack of HDAC5 $-/-$ had a significant effect $(p<0.001)$, but not significance was observed in the A $\beta$ PP background. ${ }^{\&} p<0.05$ versus WT using student's $t$-test. E) Freezing behavior in the tone-dependent memory test was significantly reduced in HDAC5 - /- and AßPP-HDAC5 - /- but not in AßPP mice when compared to WT control mice (Interaction: $\mathrm{F}_{(1,37)}=1.37, p=0.43 ;$ Hdact5 -l-: $\left.\mathrm{F}_{(1,37)}=15.53, p<0.001 ; \mathrm{A} \beta P P: \mathrm{F}_{(1,37)}=0.46, p=0.50\right)$. Bonferroni post-hoc test indicated that not only in mice lacking A $\beta P P$ pathology, the lack of HDAC $5-/-$ had a significant effect $\left({ }^{* *} p<0.01\right)$, but this effect was also significant in the A $\beta P P$ background $\left({ }^{*} p<0.01\right)$. ${ }^{\&} p<0.05$ versus A $\beta P P$ using student's $t$-test. $n=8-12$ group. Error bars indicate SEM.

non-significant $\quad\left(\mathrm{A} \beta P P: \quad \mathrm{F}_{(1,42)}=3.36, \quad p=0.07\right)$. Interestingly, in direct comparison to the $\mathrm{A} \beta \mathrm{PP}$ group, the number of platform crossings was significantly impaired in the AßPP-HDAC5 -/- group (Fig. 1F). In conclusion, this data indicates that spatial memory performance is impaired in HDAC5-/- mice, an effect that is slightly enhanced in the context of amyloid pathology.

We also analyzed associative memory employing the context and tone-dependent Pavlovian fear-conditioning paradigm. The distance traveled (Fig. 2A), the activity, and the response to electric foot-shock (Fig. 2B) during the training were comparable among groups. Moreover, only baseline freezing behavior was observed in all groups during the training procedure (Fig. 2C) suggesting that sensory processing was not affected. When re-exposed to the conditioning context $24 \mathrm{~h}$ after the training, A $\beta P P$ mice showed significantly reduced freezing behavior indicative of impaired hippocampus-dependent associative learning (Fig. 2D). Freezing behavior was also impaired in HDAC5 -/- mice when compared to the WT control group (Fig. 2D). A similar finding was observed in the AßPP-HDAC5 -/- group (Fig. 2D). However, A $\beta P P-H D A C 5 ~-/-$ mice did not significantly differ from either A $\beta P P$ or HDAC5 -/- mice (Fig. 2D). Tonedependent memory that requires proper function of the amygdala was assessed in the same groups of mice. A $\beta P P$ mice showed a trend for impaired memory consolidation that, however, was not statistical significant when compared to the WT control group (Fig. 2E). In contrast, HDAC5 -/- mice showed reduced freezing behavior when compared to the WT control group suggesting that tone-dependent memory consolidation is disturbed in HDAC5 -/- mice (Fig. 2E). In line with this finding, AßPP-HDAC5 -/- mice displayed impaired freezing behavior when compared to the WT control group and the A $\beta$ PP group. Freezing behavior 
A

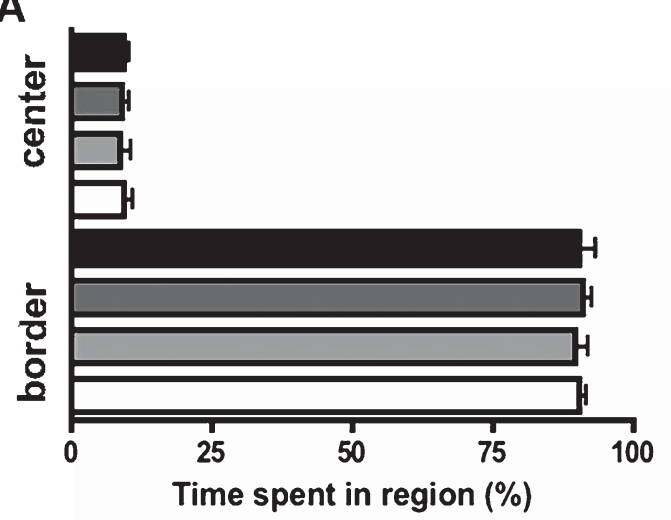

C

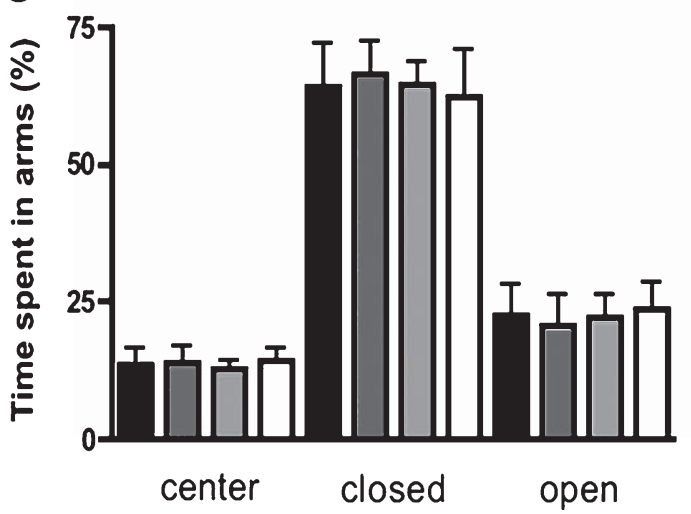

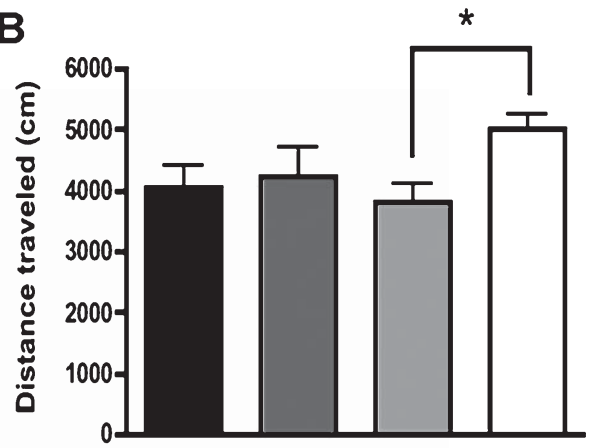

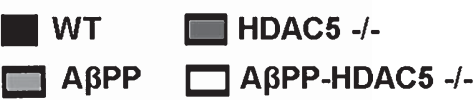

Fig. 3. Basal anxiety and explorative behavior in HDAC5 - /- mice. A) Basal anxiety assessed via the open field test was not altered among groups. Center (Interaction: $\mathrm{F}_{(1,49)}=0.11, p=0.74 ;$ Hdact5-/-: $\left.\mathrm{F}_{(1,49)}=0.01, p=0.90 ; \mathrm{A} \beta P P: \mathrm{F}_{(1,49)}=0.00, p=0.95\right)$; Border $\left(\right.$ Interaction: $\mathrm{F}_{(1,51)}=0.01$, $p=0.94$; Hdact $5-/-: \mathrm{F}_{(1,51)}=0.09, p=0.76$; A $\left.\beta P P: \mathrm{F}_{(1,51)}=0.06, p=0.81\right)$. B) Explorative behavior was similar among WT, HDAC5 -/-, and A $\beta P P$ mice. A $\beta P P-H D A C 5-/-$ mice displayed enhanced activity when compared to the A $\beta P P$ group (Interaction: $\mathrm{F}_{(1,49)}=1.98, p=0.16$; Hdact $\left.5-/-: \mathrm{F}_{(1,49)}=3.67, p=0.06 ; \mathrm{A} \beta \mathrm{PP}: \mathrm{F}_{(1,49)}=0.5989, p=0.44\right) .{ }^{*} p<0.05$ using Bonferroni post-hoc test. C) When exposed to the elevated plus maze test, all four groups of mice spent similar times in the center, the closed or the open arms of the maze confirming that basal anxiety in not affected. Center (Interaction: $\mathrm{F}_{(1,40)}=0.43, p=0.51 ;$ Hdact $\left.5-/-: \mathrm{F}_{(1,40)}=0.05, p=0.82 ; \mathrm{A} \beta P P: \mathrm{F}_{(1,40)}=0.03, p=0.85\right)$; Closed (Interaction: $\mathrm{F}_{(1,44)}=0.21, p=0.64 ;$ Hdact5 -l-: $\left.\mathrm{F}_{(1,44)}=0.19, p=0.66 ; \mathrm{A} \beta P P: \mathrm{F}_{(1,44)}=0.73, p=0.39\right) ;$ Open (Interaction: $\mathrm{F}_{(1,47)}=0.93, p=0.34 ;$ Hdact5 $-/-\mathrm{F}_{(1,47)}=0.03, p=0.86$; A $\left.\beta P P: \mathrm{F}_{(1,47)}=0.01, p=0.93\right) . n=15-18$ /group. Error bars indicate SEM.

among HDAC5 -/- and AßPP-HDAC5 -/- mice was not significantly different (Fig. 2E). In conclusion, this data indicates that HDAC5 plays a role in the consolidation of contextual and tone-dependent fear memories but has no impact on associative memory function in A $\beta P P$ mice.

We also assessed basal anxiety behavior using the open field and the elevated plus maze tests. No significant difference among groups was observed when the time spent in the center versus the border of the open field arena was analyzed, which presents a common measure of basal anxiety (Fig. 3A). Interestingly, the total distance traveled during the test period was increased in A $\beta P P-H D A C 5$-/- mice when compared to A $\beta P P$ mice (Fig. 3B). Although there was no main effect of amyloid pathology or HDAC5 -/-, the main effect of HDAC5 -/- was borderline non-significant $\left(\mathrm{F}_{(1,49)}=3.670, p=0.06\right)$. Nonetheless, Bonferroni post-hoc tests indicated that in mice with A $\beta P P$ pathology, the lack of HDAC5 had a significant effect (WT versus HDAC $\left.5-/-,{ }^{*} p<0.05\right)$ on the distance traveled in the open field. Basal anxiety was also analyzed in the elevated plus maze test. No difference was detected among groups (Fig. 3C). In sum, this data indicates that HDAC5 does not affect basal anxiety levels.

Finally, we analyzed amyloid pathology and hippocampal integrity. First we confirmed that the expression of the human App ( $h A p p$ ) transgene and the levels of the corresponding protein were not affected in HDAC5 -/- mice (Fig. 4A, B).

Next, we measured $A \beta$-plaque load in the hippocampal region (Fig. $4 \mathrm{C}, \mathrm{E}$ ) and the brainstem 
A

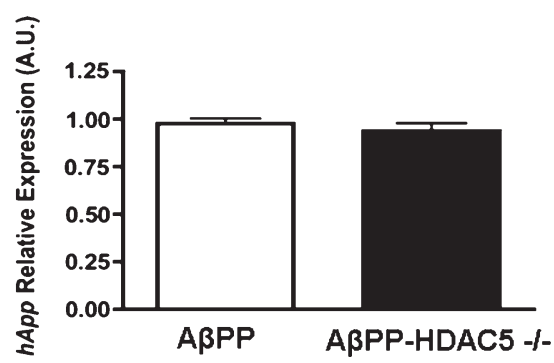

B

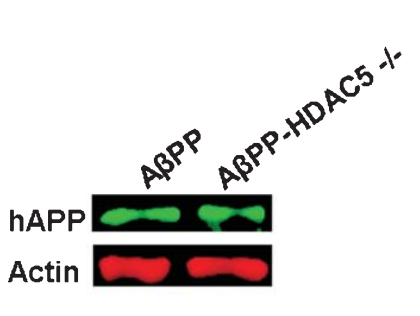

C

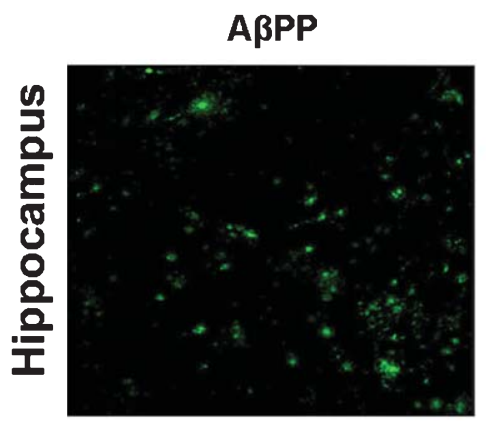

D

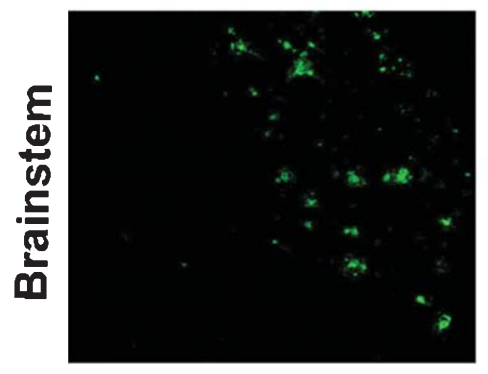

\section{AßPP-HDAC5 - -}
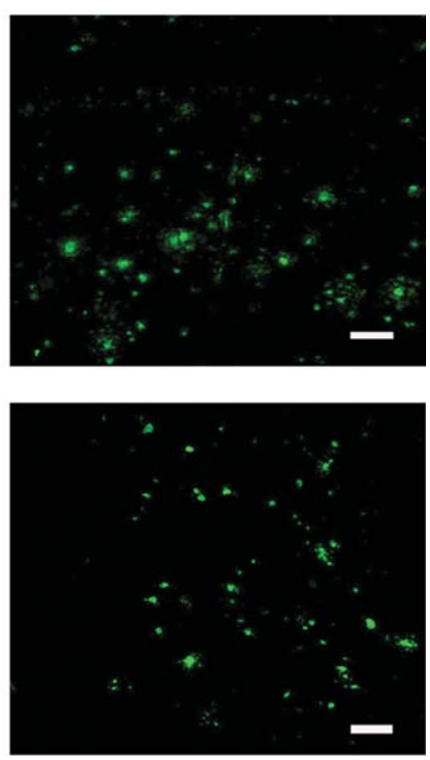

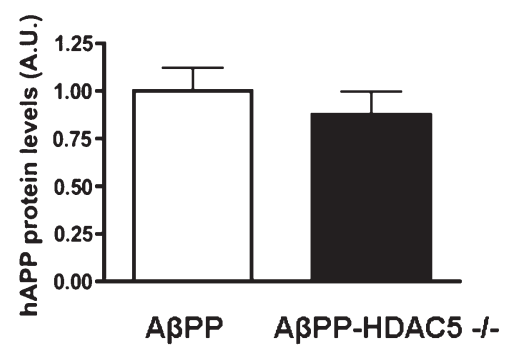

E

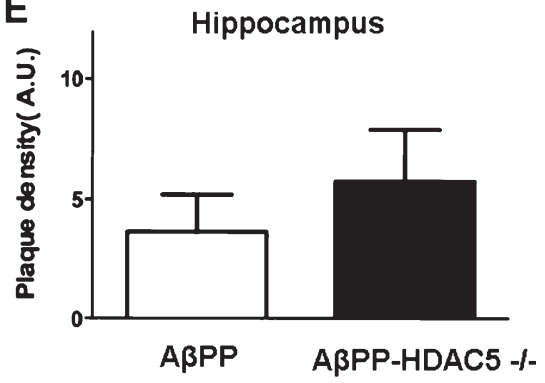

F

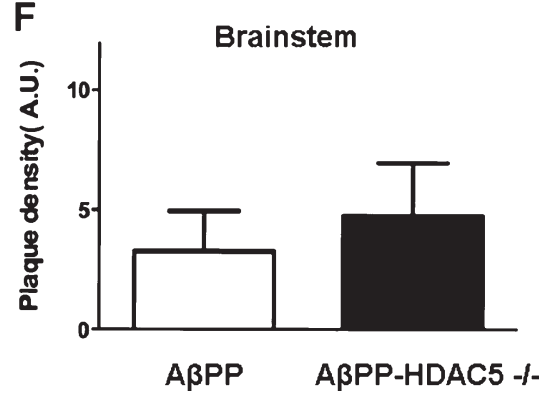

Fig. 4. Loss of HDAC5 does not affect amyloid pathology. Lack of HDAC5 does not affect either human App ( $h A p p$ ) transgene (A) or protein expressions (B) in the mice showing A $\beta P P$ pathology. Representative confocal microscopy images showing $A \beta$ plaque load in the hippocampus (C) and the brain stem (D) of A $\beta P P$ and A $\beta P P-H D A C 5-/-$ mice. Quantification of plaque load in hippocampus (E) and brainstem (F) revealed no significant difference between A $\beta P P$ and A $\beta P P-H D A C 5-/-$ mice. A.U., arbitrary units, $n=7-10 /$ group. Error bars indicate SEM.

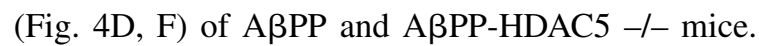
Densiometric analysis of $4 \mathrm{G} 8$ staining revealed no significant differences among groups (Fig. 4). Since WT and HDAC5 -/- mice display no amyloid pathology, these groups are not shown. We also analyzed NeuN, MAP2, synaptophsyin-38, and synaptoprorin immunoreactivity in the hippocampus, four wellestablished markers for neuronal integrity $[8,22]$. No difference was observed among groups (Fig. 5).

\section{DISCUSSION}

Deregulation of epigenetic processes such as histone-acetylation has been observed in neuropsychiatric and neurodegenerative diseases [2, 25]. In line with this, a growing body of literature suggests HDACs as promising drug targets to treat cognitive dysfunction in $\mathrm{AD}[6-9,11,13,26]$. Understand the neurobiology of individual HDAC proteins and their role in cognitive processes and the pathogenesis of neurodegenerative diseases including $\mathrm{AD}$ is therefore a vital step to develop more selective HDAC inhibitors and eventually translate these findings into clinical application.

In this study we investigated the contribution of HDAC5 to learning and memory processes and the pathogenesis of AD in a rodent model. To our knowledge, this is the first study to address these questions. Our data shows that loss of HDAC5 leads to impaired spatial and associative memory function in mice. Although HDAC5 -/- mice show normal explorative behavior and display no deficits in motor function and basal anxiety, we cannot exclude the impact of 

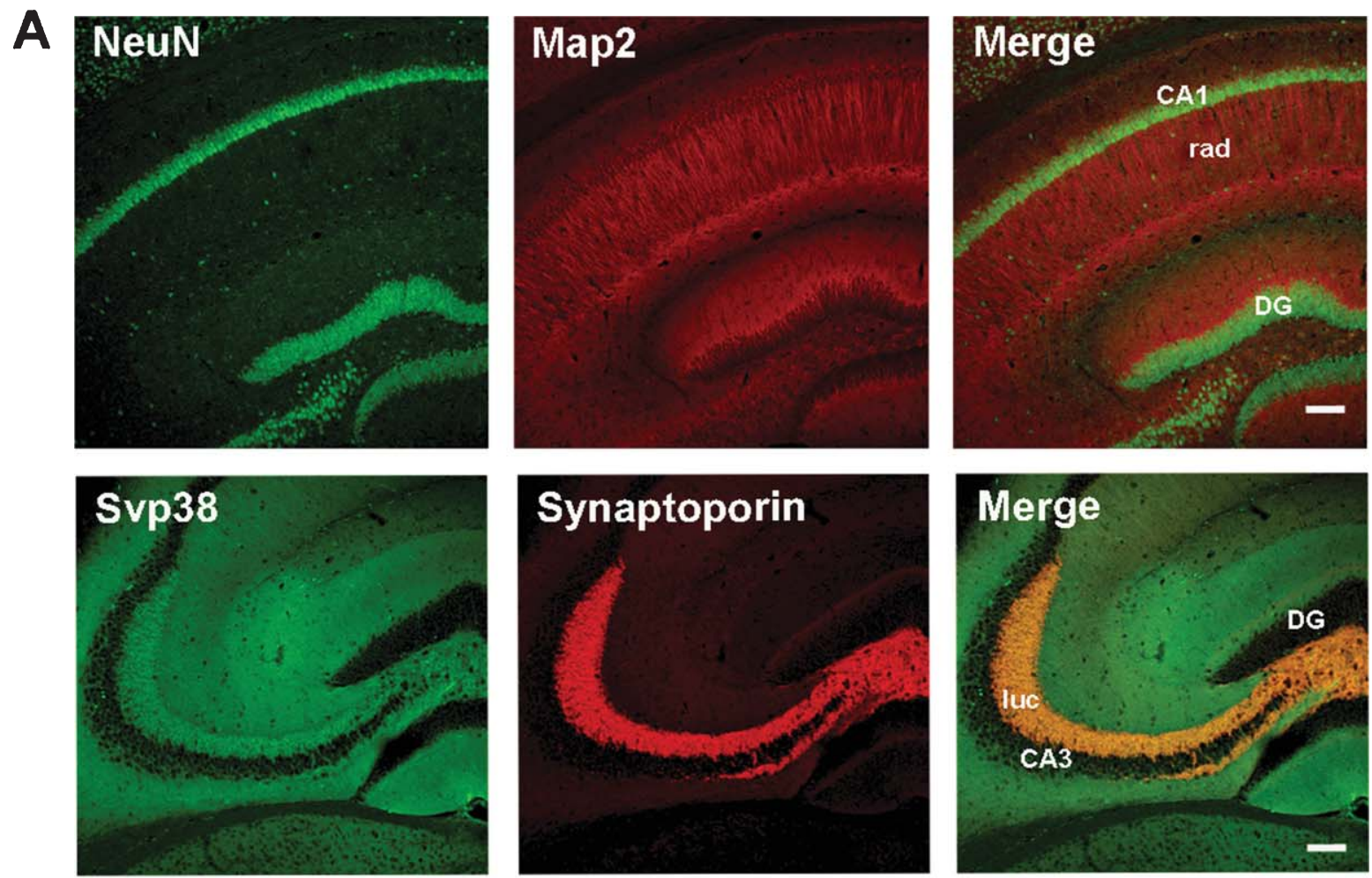

B
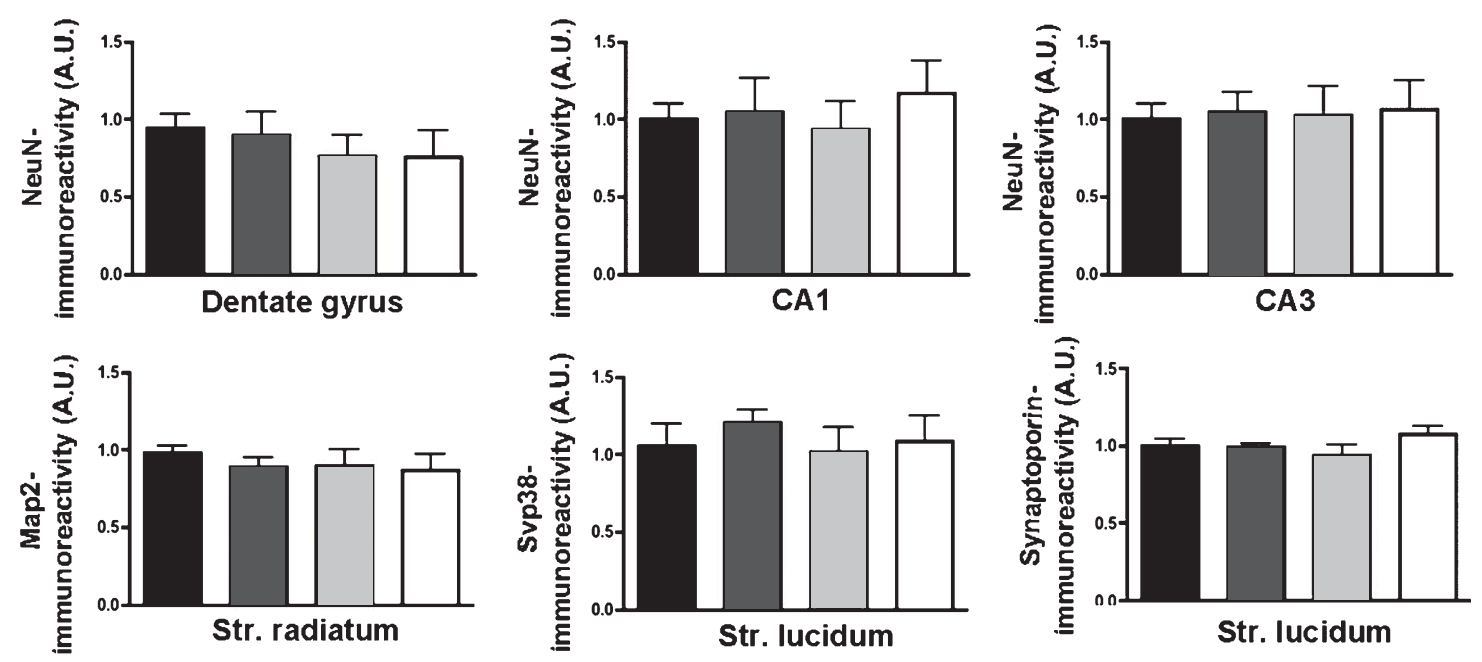

WT

HDAC5 $-1-$ AßPP

ABPP-HDAC5 -/-

Fig. 5. Loss of HDAC5 does not cause overt changes in hippocampal integrity. A) Representative images showing immunoreactivity for NeuN, Map2, synaptophysin-38, and synaptoporin protein levels in the hippocampal formation of WT mice. Scale bar: $100 \mu \mathrm{m}$. B) Quantification of NeuN, Map2, synaptophysin-38 (Svp38), and synaptoporin immunoreactivity revealed no differences among groups. NeuN-dentate gyrus: Interaction: $\mathrm{F}_{(1,27)}=0.00, p=0.98 ;$ Hdact5 -l-: $\left.\mathrm{F}_{(1,27)}=0.08, p=0.78 ; \mathrm{A} \beta P P: \mathrm{F}_{(1,27)}=0.01, p=0.92\right) ;$ NeuN-CA1: Interaction: $\mathrm{F}_{(1,35)}=1.01, p=0.32$; Hdact5 -l-: $\left.\mathrm{F}_{(1,35)}=1.08, p=0.30 ; \mathrm{A} \beta P P: \mathrm{F}_{(1,35)}=0.93, p=0.34\right)$; NeuN-CA3: Interaction: $\mathrm{F}_{(1,34)}=0.00, p=0.96 ;$ Hdact5 -l-: $\mathrm{F}_{(1,34)}=0.08$, $p=0.77$; АßPP: $\left.\mathrm{F}_{(1,34)}=0.02, p=0.89\right)$; Map2: Interaction: $\mathrm{F}_{(1,29)}=0.18, p=0.67 ;$ Hdact5 -l-: $\mathrm{F}_{(1,29)}=0.55, p=0.46 ; \mathrm{A} \beta P P: \mathrm{F}_{(1,29)}=0.40$, $p=0.53)$; Svp38: Interaction: $\mathrm{F}_{(1,28)}=0.17, p=0.68 ;$ Hdact5 -l-: $\left.\mathrm{F}_{(1,28)}=0.69, p=0.41 ; \mathrm{A} \beta P P: \mathrm{F}_{(1,28)}=0.10, p=0.74\right)$; Synaptoporin: Interaction: $\mathrm{F}_{(1,33)}=1.85, p=0.18$; Hdact5 - -l-: $\left.\mathrm{F}_{(1,33)}=1.38, p=0.24 ; \mathrm{A} \beta \mathrm{PP}: \mathrm{F}_{(1,33)}=0.06, p=0.80\right)$; rad, stratum radiatum; luc, stratum lucidum; CA1, CA1 pyramidal layer; CA3, CA3 pyramidal layer; DG, dentate gyrus; A.U., arbitrary units. $n=8 /$ group Error bars indicate SEM. 
developmental processes on the observed phenotypes. Since, previous studies have demonstrated that administration of pan-HDAC inhibitors facilitate these types of memories [14, 27-29], our data strongly supports the view that inhibition of HDAC5 is not responsible for this effect. In contrary, our data suggest that inhibition of HDAC5 would be detrimental. In this context it is interesting to mention that previous findings implicated HDAC5 with cocaine addiction, an extreme form of synaptic plasticity and learning behavior [18], suggesting a more general role for HDAC5 in memory consolidation. In contrast to other HDACs such as HDAC2 that was shown to act a constraint of memory consolidation [14], our data indicates that HDAC5 is essential for memory function. While the underlying mechanisms remain to be elucidated, it is interesting to note that HDAC5 has been implicated with histonedeacetylation [17] and deacetylation of non-histone proteins such as MEF2 which regulates synaptic plasticity $[16,30]$. In line with the observation that HDAC5 is essential for memory formation, loss of HDAC5 did not improve spatial and associative memory function in a mouse model for AD. Previous studies have shown that HDAC inhibitors improve cognitive function in AD mouse models [1, 6-9, 11, 13]. Our data strongly suggest that this effect is independent of HDAC5 inhibition. In fact that there was a trend for further impaired memory function in HDAC5 -/- mice when compared to A $\beta$ PP mice suggesting that targeting HDAC5 should be avoided when developing novel HDAC inhibitors. In general our data support the view that class I HDACs might be better targets to treat memory dysfunction [7, 14], while class II HDACs, such as HDAC5 that might have a broader role on various cellular mechanisms [1, 31], would not be bona fide drug targets.

In conclusion, our study adds important knowledge to the fast growing research area investigating the role of HDACs as drug targets to treat AD. Recent data suggested that HDAC2 [14, 15], HDAC3 [32], and also HDAC6 [33] might be suitable drug targets to treat cognitive decline. In contrast, targeting HDAC1, which is essential to regulate fear extinction in mice [34], appears less promising. Our data now clearly demonstrates that targeting HDAC5 should be avoided in future drug development programs.

\section{ACKNOWLEDGMENTS}

We thank E. Olson for providing HDAC5 knockout mice. This work was partially supported the EUYRI award of the European Science Foundation, funds from the German Center for Neurodegenerative diseases (DZNE), the Schram foundation, the Hans and Ilse Breuer foundation and the ERA-Net Neuron project EPITHERAPY to AF. RCAB was supported by an EMBO Long-term fellowship.

Authors' disclosures available online (http://www.jalz.com/disclosures/view.php?id=1443).

\section{REFERENCES}

[1] Fischer A, Sananbenesi F, Mungenast A, Tsai LH (2010) Targeting the right $\mathrm{HDAC}(\mathrm{s})$ to treat congitive diseases. Trends Pharmacol Sci 31, 605-617.

[2] Sananbenesi F, Fischer A (2009) The epigenetic bottleneck of neurodegenerative and psychiatric diseases. Biol Chem 390, 1145-1153.

[3] Stilling RM, Fischer A (2011) The role of histone acetylation in age-associated memory impairment and Alzheimer's disease. Neurobiol Learn Mem 96, 19-26.

[4] Shahbazian MD, Grunstein M (2007) Functions of sitespecific histone acetylation and deacetylation. Anпu Rev Biochem 76, 75-100

[5] Fischer A, Sananbenesi F, Wang X, Dobbin M, Tsai LH (2007) Recovery of learning \& memory after neuronal loss is associated with chromatin remodeling. Nature 447, 178182.

[6] Ricobaraza A, Cuadrado-Tejedor M, Pérez-Mediavilla A, Frechilla D, Del Río J, García-Osta A (2009) Phenylbutyrate ameliorates cognitive deficit and reduces tau pathology in an Alzheimer's disease mouse model. Neuropsychopharmacology 34, 1721-1732.

[7] Kilgore M, Miller CA, Fass DM, Hennig KM, Haggarty SJ, Sweatt JD, Rumbaugh G (2010) Inhibitors of class 1 histone deacetylases reverse contextual memory deficits in a mouse model of Alzheimer's disease. Neuropsychopharmacology 35, 870-880.

[8] Peleg S, Sananbenesi F, Zovoilis A, Burkhardt S, Bahari-Java S, Agis-Balboa RC, Cota P, Wittnam J, Gogul-Doering A, Opitz L, Salinas-Riester G, Dettenhofer M, KAng H, Farinelli L, Chen W, Fischer A (2010) Altered histone acetylation is associated with age-dependent memory impairment in mice. Science 328, 753-756.

[9] Francis YI, Fà M, Ashraf H, Zhang H, Staniszewski A, Latchman DS, Arancio O (2009) Dysregulation of histone acetylation in the APP/PS1 mouse model of Alzheimer's disease. J Alzheimers Dis 18, 131-139.

[10] Fontán-Lozano A, Romero-Granados R, Troncoso J, Múnera A, Delgado-García JM, Carrión AM (2008) Histone deacetylase inhibitors improve learning consolidation in young and in KA-induced-neurodegeneration and SAMP-8-mutant mice. Mol Cell Neurosci 39, 193-201.

[11] Ricobaraza A, Cuadrado-Tejedor M, Marco S, Pérez-Otaño I, García-Osta A (2012) Phenylbutyrate rescues dendritic spine loss associated with memory deficits in a mouse model of Alzheimer disease. Hippocampus 22, 1040-1050.

[12] Dash PK, Orsi SA, Moore AN (2009) Histone deactylase inhibition combined with behavioral therapy enhances learning and memory following traumatic brain injury. Neuroscience 163, $1-8$.

[13] Govindarajan N, Agis-Balboa C, Walter J, Sananbenesi F, Fischer A (2011) Sodium butyrate improves memory function in an Alzheimer's disease mouse model when administered 
at an advanced stage of disease progression. J Alzheimers Dis 24, 1-11.

[14] Guan JS, Haggarty SJ, Giacometti E, Dannenberg JH, Joseph N, Gao J, Nieland TJ, Zhou Y, Wang X, Mazitschek R, Bradner JE, DePinho RA, Jaenisch R, Tsai LH (2009) HDAC2 negatively regulates memory formation and synaptic plasticity. Nature 459, 55-60.

[15] Gräff J, Rei D, Guan JS, Wang WY, Seo J, Hennig KM, Nieland TJ, Fass DM, Kao PF, Kahn M, Su SC, Samiei A, Joseph N, Haggarty SJ, Delalle I, Tsai LH (2012) An epigenetic blockade of cognitive functions in the neurodegenerating brain. Nature $\mathbf{4 8 3}, 7388$

[16] Flavell SW, Cowan CW, Kim TK, Greer PL, Lin Y, Paradis S, Griffith EC, Hu LS, Chen C, Greenberg ME (2006) Activity-dependent regulation of MEF2 transcription factors suppresses excitatory synapse number. Science 311, 10081012.

[17] Tsankova NM, Berton O, Renthal W, Kumar A, Neve RL, Nestler EJ (2006) Sustained hippocampal chromatin regulation in a mouse model of depression and antidepressant action. Nat Neurosci 9, 519-525.

[18] Renthal W, Maze I, Krishnan V, Covington HEr, Xiao G, Kumar A, Russo SJ, Graham A, Tsankova N, Kippin TE, Kerstetter KA, Neve RL, Haggarty SJ, McKinsey TA, BasselDuby R, Olson EN, Nestler EJ (2007) Histone deacetylase 5 epigenetically controls behavioral adaptations to chronic emotional stimuli. Neuron 56, 517-529.

[19] Taniguchi M, Carreira MB, Smith LN, Zirlin BC, Neve RL, Cowan CW (2012) Histone deacetylase 5 limits cocaine reward through cAMP-induced nuclear import. Neuron 73, 108-120.

[20] Radde R, Bolmont T, Kaeser SA, Coomaraswamy J, Lindau D, Stoltze L, Calhoun ME, Jäggi F, Wolburg H, Gengler S, Haass C, Ghetti B, Czech C, Hölscher C, Mathews PM, Jucker M (2006) Abeta42-driven cerebral amyloidosis in transgenic mice reveals early and robust pathology. EMBO Rep 7, 940946.

[21] McKinsey TA, Zhang CL, Lu J, Olson EN (2000) Signaldependent nuclear export of a histone deacetylase regulates muscle differentiation. Nature 408, 106-111.

[22] Agis-Balboa RC, Arcos-Diaz DA, Wittnam J, Govindarajan N, Blom K, Burkhardt S, Haladyniak U, Agbemenyah HY, Zovoilis A, Salinas-Riester G, Opitz L, Sananbenesi F, Fischer A (2011) A hippocampal insulin-growth factor 2 pathway regulates the extinction of fear memories. EMBO J 30, 4071-4083.

[23] Kuczera T, Stilling RM, Hsia HE, Bahari-Javan S, Irniger S, Nasmyth K, Sananbenesi F, Fischer A (2010) The anaphase promoting complex is required for memory function in mice. Learn Mem 18, 49-57.
[24] Schang LM (2004) Effects of pharmacological cyclindependent kinase inhibitors on viral transcription and replication. Biochim Biophys Acta 1697, 197-209.

[25] Tsankova N, Renthal W, Kumar A, Nestler EJ (2007) Epigenetic regulation in psychiatric disorders. Nat Rev Neurosci 8 , 355-367.

[26] Fischer A (2010) HDAC Inhibitoren als Therapie für Neuronale Erkrankungen. Pharm Unserer Zeit 39, 204-209.

[27] Levenson JM, O'Riordan KJ, Brown KD, Trinh MA, Molfese DL, Sweatt JD (2004) Regulation of histone acetylation during memory formation in the hippocampus. J Biol Chem $\mathbf{2 7 9}$, 40545-40559.

[28] Alarcon JM, Malleret G, Touzani K, Vronskaya S, Ishii S, Kandel ER, Barco A (2004) Chromatin acetylation, memory, and LTP are impaired in $\mathrm{CBP}+/-$ mice: A model for the cognitive deficit in Rubinstein-Taybi syndrome and its amelioration. Neuron 42, 947-959.

[29] Korzus E, Rosenfeld MG, Mayford M (2004) CBP histone acetyltransferase activity is a critical component of memory consolidation. Neuron 42, 961-972.

[30] Belfield JL, Whittaker C, Cader MZ, Chawla S (2006) Differential effects of $\mathrm{Ca} 2+$ and cAMP on transcription mediated by MEF2D and cAMP-response element-binding protein in hippocampal neurons. J Biol Chem 281, 277-232.

[31] Lahm A, Paolini C, Pallaoro M, Nardi MC, Jones P, Neddermann P, Sambucini S, Bottomley MJ, Lo Surdo P, Carfí A, Koch U, De Francesco R, Steinkühler C, Gallinari P (2007) Unraveling the hidden catalytic activity of vertebrate class IIa histone deacetylases. Proc Natl Acad Sci U S A 104, 1733517340.

[32] McQuown SC, Barrett RM, Matheos DP, Post RJ, Rogge GA, Alenghat T, Mullican SE, Jones S, Rusche JR, Lazar MA, Wood MA (2010) HDAC3 is a critical negative regulator of long-term memory formation. J Neurosci 31, 764-774.

[33] Rivieccio MA, Brochier C, Willis DE, Walker BA, D'Annibale MA, McLaughlin K, Siddiq A, Kozikowski AP, Jaffrey SR, Twiss JL, Ratan RR, Langley B (2009) HDAC6 is a target for protection and regeneration following injury in the nervous system. Proc Natl Acad Sci U S A 106, 1959919604.

[34] Bahari-Javan S, Maddalena A, Kerimoglu C, Wittnam J, Held T, Bähr M, Burkhardt S, Delalle I, Kügler S, Fischer A, Sananbenesi F (2012) HDAC1 regulates fear extinction in mice. $J$ Neurosci 32, 5062-5073. 